\title{
Research on the Profit Model of the Asset-light Operation Driven by Financial Strategy
}

\author{
Shao-Yan Zhou ${ }^{1, \text { a }}$ \\ ${ }^{1}$ Department of Economics, China University Of Geosciences Great Wall College,Baoding, China \\ azhoushaoyan627@163.com
}

Keywords: Driven by Financial Strategy; Asset-light; Operating characteristics; Profit Model

\begin{abstract}
There are inextricably linked between financial strategy and asset-light business model. The profit model of the asset-light was driven by financial strategy, and the corporate operating model will need to match the financial strategy. First, asset light theory, asset light operating profit and asset-light model and other theories must be clear. And then, on the basis of this, the intrinsic link between financial strategy and profit model asset-light operation is analyzed to establish the theoretical framework of financial strategy driven asset light operating profit model. Finally, taking HE Company as an example, the empirical research is carried out.
\end{abstract}

\section{Introduction}

Currently, light-asset management is widely used by more and more business entities. They often invest the minimum capital to leverage and integrate a variety of quality resources inside and outside the enterprises depending on their long-term accumulation of customer resources, brand culture, technology research and development, human resources and other asset-light, which achieves the benefit of throwing a sprat to catch a herring and creates a unique company's competitive advantage and corporate value. Asset-light profit model, as a new model of sustainable profitability, are still at the exploratory stage both in theory and in applications ${ }^{[1]}$. Currently, researches on asset-light are mainly focused on the strategic level, usually analyze success and failure cases of the asset-light business model, rather than study asset-light operating profit model from the perspective of financial management, so it's difficult to practice light asset management companies to give effective guidance. However, sustainable development is inseparable from the company's efficient financial management strategies. Financial strategy is to meet the company's overall competitive strategy and raise the necessary funds and to use these funds effectively within the organization, which is a vital part of their overall strategy ${ }^{[2,3]}$. There are inextricably linked between financial strategy and asset-light business model, asset-light management profit model was driven by financial strategy, and the corporate operating model will need to match the financial strategy.

In this paper, we analyze the content of asset-light and the theoretical framework of asset-light operations driven by financial management and then take HE Company as an empirical research.

\section{Basic Theory}

\section{Definition of Asset-light}

Currently, domestic and foreign researchers have done a lot of researches on the asset-light, but have not yet formed a clear and detailed definition ${ }^{[4]}$. McKinsey, which is an internationally renowned management consulting agency, regard the corporate brand, manpower, experience and client resources, values, governance, management processes as asset-light. "Business" magazine define asset-light as "the maximum with a minimum of funds leveraging resources, earn the most profit" in a straightforward language. Wong Jing (2008) pointed out that "asset-light" is relative to take up a lot of money in terms of weight assets, including brand, customer relationships, human resources, standardized process management, corporate experience and so on. From the above content, asset-light is the asset that enterprises form and accumulate in the long-term business, including brand 
patents, corporate values and culture, human resources, management systems and processes, knowledge assets, channels and networks as well as all aspects of the relationship between resources, which is a key factor in business continuity cash flows and maximizing the value.

\section{Theoretical of Asset-light Operations}

The core theory of asset-light strategy is the mental resources that enterprises adopt to maximize profit margins easily, replace manual labor that is difficult to create value, and leave a large number of manufacturing sectors to the foundry and outsourcing companies. The companies that use light asset management strategy will be more sustainable and competitive with respect to competitors in profitability. The strategic objectives of asset-light management is to maximize shareholder value and maximum investment return rate, grasping the changing consumer demand, declining investment in asset-heavy part of the enterprise in order to increase the cost of the asset-light, market share and maintain resources. Asset-light management is a business model that can enable enterprises to have access to resources, configuration, integration, and ability to respond quickly to market changes.

\section{Connotation of Asset-light Management Profit Model}

According to the analysis of domestic and foreign scholars on asset-light profit model, this paper will summarize the connotation of asset-light profit model as follows: asset-light business profit model is combined with the industry characteristics and value chain structure, use the asset-light business resources and capacity utilization to leverage other resources of the enterprises to optimize the reconstruction of a combination of their business system with a lowest capital investment and maximize value and obtain continuing revenue streams and unique corporate cash flow ${ }^{[5]}$.

\section{Theoretical Framework of Asset-light Operating Profit Mode Driven by Financial Strategy}

There are some inseparable connection exists between financial strategy and profit model asset-light operations. The core of profit model is to guide and safeguard business to earn excess profits continuity continuously. The purpose of financial management is to locate the target of enterprises at the enterprise value, especially value of shareholder. The value of enterprise is the final standard to judge the profit model, which means that the profit model is the bridge to connect the customer value and business investment. Financial Strategic Planning finally appear as a result of financial performance, results of financial performance acts on the financial strategy in turn. Only through constantly adjust financial strategies, promote the improvement of profit model, enterprise obtain better financial results.

Corporate strategy is equals to choose a profit mode, and profit model reflects the strategy has been implemented, and the value of strategic is to make choices and flexible configuration of profit model. Financial Strategy subordinates corporate strategy, and is the subject of corporate strategy, have a significant impact on all aspects of corporate strategy. Enterprises need to focus on cash flow in the development of financial strategies. Therefore, asset-light profit model is essentially a powerful enterprise resource acquisition, configuration, integration, and ability to respond quickly to market changes. Enterprises which use asset-light profit model and want to maintain its leadership position and their revenues in the profit model network system, to maintain their earnings and cash flow, companies must analyze their own set of policies implemented from the perspective of the value chain to promote the further development of asset-light profit model. Enterprises can combine enterprise value drivers which were proposed in business value model, and analyze of asset-light profit model from the perspective of the value chain and combining these eight points in profit model: product strategy, procurement strategy, sales strategy, operation strategy, research strategy, capital strategy, financing strategy and cash strategy.

In summary, we can get the theoretical framework of asset-light operating profit model driven by financial strategy, as Figure.1 shows. 


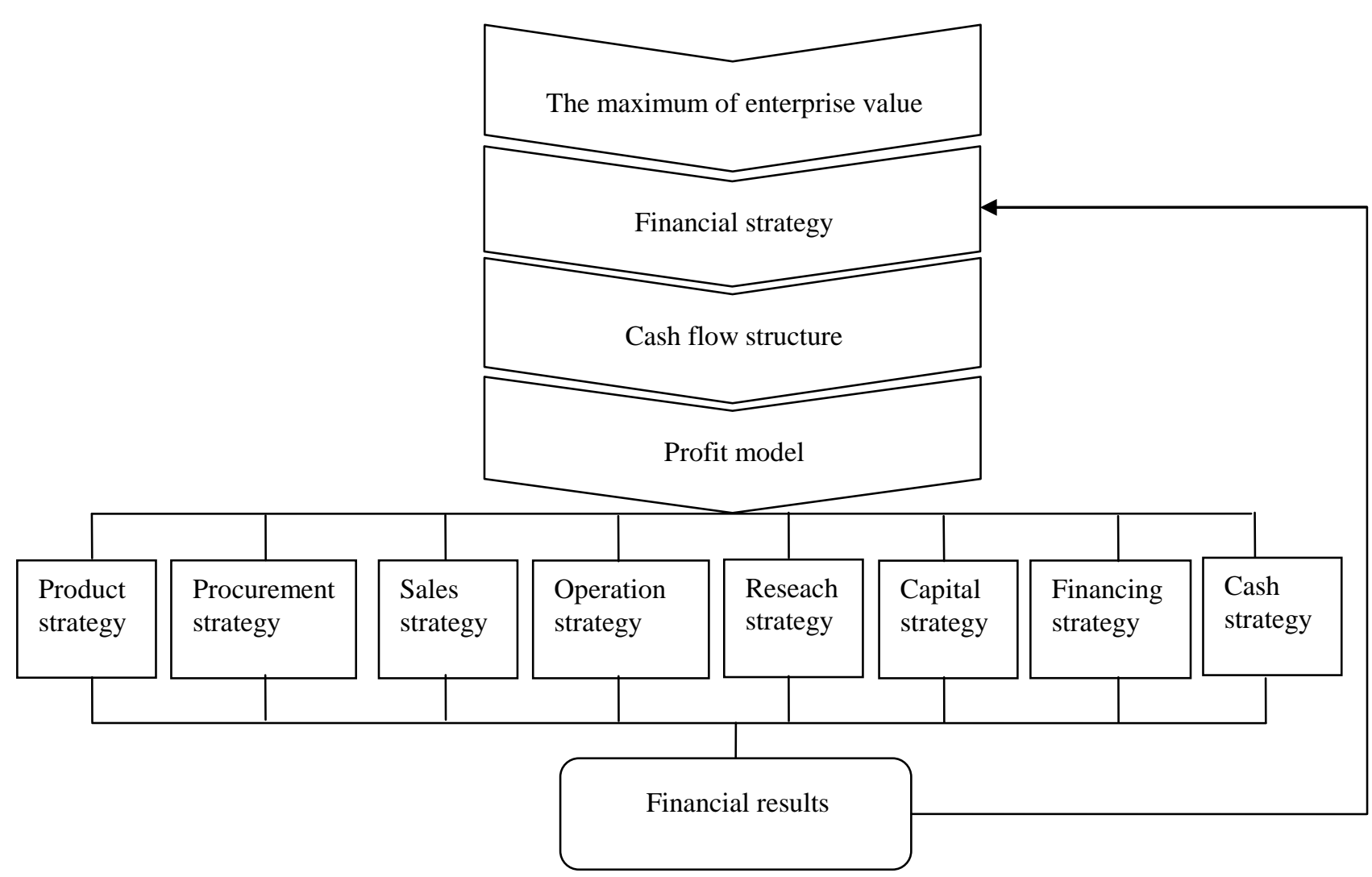

Fig.1 The theoretical framework of the profit model of the asset-light operation driven by financial strategy

\section{An Empirical Study of HE Company}

\section{The Basic Situation of HE Company}

The business scope of HE Company is more extensive, including electrical appliances, electronic products, import and export business, real estate development and other areas, which has been provided with full internal and external conditions for the implementation of asset-light profit model. The company has a good quality of earnings. As of the end of 2014, its total operating income was 79.857 billion yuan, its net profit was 4.36 billion yuan, its gross margin reached $25.24 \%$, and its net cash flow from operating activities reached 5.519 billion yuan. The asset-light management of HE Company mainly includes three aspects of supply chain management, brand management and customer relationship management.

Financial Characteristics Analysis of HE Company's Profit Model of Asset-light Operation

By analyzing the asset structure of HE Company in the past ten years, we get the financial characteristics of the profit model under the asset-light operation, mainly respecting in the following two aspects:

High current assets. The proportion of liquid assets in HE Company is higher and is rising year by year, seeing in table 1 . In 2005, the ratio of current assets in total assets is $54.52 \%$, which has increased to $79.90 \%$ in the year of 2014. Especially in the past four years, the current assets ratio of HE Company remained at around 80\%. A higher proportion of current assets provide guarantee for the implementation of asset-light profit model and the steady increase in cash flow, as shown in Table 1. 
Table 1 The current assets of HE Company in the year of 2005-2014

\begin{tabular}{ccccccccccc}
\hline Years & 2005 & 2006 & 2007 & 2008 & 2009 & 2010 & 2011 & 2012 & 2013 & 2014 \\
\hline $\begin{array}{c}\text { Total assets } \\
\text { (million yuan) }\end{array}$ & 7373 & 7107 & 6777 & 8477 & 11189 & 12231 & 22702 & 29267 & 39784 & 49688 \\
$\begin{array}{c}\text { Current assets } \\
\text { (million yuan) } \\
\begin{array}{c}\text { The ratio of } \\
\text { current assets (\%) }\end{array}\end{array}$ & 5020 & 3958 & 3845 & 5584 & 7791 & 7863 & 17910 & 23571 & 31394 & 39700 \\
\hline
\end{tabular}

(2) High current liabilities. In recent ten years, the proportion of current liabilities in HE Company has maintained a relative growth trend. In the year of 2005, the ratio of current liabilities accounted for the proportion of $18.88 \%$ only, while in the year of 2014 the proportion was as high as $63.08 \%$, increasing 2.34 times. And in recent years, the ratio was relatively stable and basically maintained at around 64\%, as shown in Table 2.

Table 2 The current liabilities of HE Company in the year of 2005-2014

\begin{tabular}{ccccccccccc}
\hline Years & 2005 & 2006 & 2007 & 2008 & 2009 & 2010 & 2011 & 2012 & 2013 & 2014 \\
\hline $\begin{array}{c}\text { Total assets } \\
\text { (million yuan) }\end{array}$ & 7373 & 7107 & 6777 & 8477 & 11189 & 12231 & 22702 & 29267 & 39784 & 49688 \\
$\begin{array}{c}\text { Current liabilities } \\
\text { (million yuan) }\end{array}$ & 1392 & 783 & 722 & 2107 & 4043 & 4445 & 12079 & 18673 & 25969 & 31341 \\
$\begin{array}{c}\text { The ratio of current } \\
\text { liabilities (\%) }\end{array}$ & 18.88 & 11.02 & 10.65 & 24.86 & 36.13 & 36.34 & 53.29 & 63.80 & 65.27 & 63.08 \\
\hline
\end{tabular}

The Profit Model Effect Analysis on HE Company Driven by Financial Strategy

HE Company forms its own asset-light profit model strategy based on product strategy, procurement strategy, sales strategy, operation strategy, research strategy, capital strategy, financing strategy and cash strategy. Meantime, the related business activities and capital behaviors are managed and controlled financially, and eventually the good financial performance was won to further promote the enterprise value maximization.

(1) Product strategy effect analysis. Relying on its own advantages of resources, HE Company attracts more third customers, including home appliances, furniture and online retail platform, to constantly innovate new profit growth point and constantly improve the company's gross profit margin.

(2) Procurement strategy effect analysis. A whole industry chain mode of supply chain management model is built to reasonably manage the procurement channels, producing channels and the turnover time of funds. The whole supply chain is rapid, accurate and efficient, further reducing the revenue cost and promoting asset-light profit model.

(3) Sales strategy effect analysis. HE Company continues to promote the marketing model of "combination of virtual and real network with zero distance" and achieves good sales performance. By improving the marketing model, the company continues to show steady growth in revenue, which provides a solid foundation for the sustainable development of HE Company's profitability.

(4) Operation strategy effect analysis. HE Company creates a new inventory management pattern of "zero inventory" and implements. Taking good control of management and operation activities such as accounts receivable, inventory, and payable account is useful to improve the company's asset-light sustainable profitability and the enterprise value.

(5) Research strategy effect analysis. HE Company continues to carry out technological innovation, technology strategic alliances and mergers and acquisitions, giving full play to the integration effect. It has formed "the whole process of parallel open and interactive innovation ecological system" to provide core driving force for the continuous increase of enterprises operating income. 
(6) Capital strategy effect analysis. Under the guidance of service transformation direction, HE Company continues to reduce the investment growth rate of fixed asset as well as the proportion of the fixed assets accounted for total assets. In nearly three years, the proportion of fixed assets is maintained at around 11\%, and the capital operation and financial control of fixed assets is helpful for the achievement of good financial performance.

(7) Financing strategy effect analysis. HE Company adheres to strengthen internal financing policy, and continues to promote the diversification of financing means, making the company obtain more resources by lower cost of capital leverage. It can promote enterprise asset-light operations and lay the foundation for the improvement of enterprise value.

(8) Cash strategy effect analysis. HE Company timely adjusts the sale remittances policy and optimizes the transfer structure, maintaining a substantial increase in net cash flow from operating activities. Paying attention to and strengthening the management of cash flow can effectively promote the sustainable development of the company and improve the company's market competitiveness.

\section{Conclusion}

This article constructed a theoretical framework of asset light operating profit model driven by financial management and took HE company as an example, analyzed the financial characteristics of the asset-light operating profit mode and the profit effects driven by financial strategy of HE company. From the research, company which uses the asset-light business mode must have a forward-looking strategic financial arrangement and pave quality strategic layout for the various categories of strategic initiatives.

\section{References}

[1] McKinsey. Asset-light strategy, leaving only the technology and brand, J. Competitiveness. 5 (2002) 118-119.

[2] Du Haixia. On the Asset-light Business Model--Based on Huayi Brothers Case Study, J. Accounting Monthly. 27 (2015) 112-113.

[3] Hao Wei. Asset-light business model leveraging enterprise value maximization -- Based on Tencent Finance Case Study, J. New accounting. 11(2013) 26-29.

[4] Mou Jingjing, Zhou Changlin. The financial strategy selection of the asset-light model company, J. International Business Accounting. 11(2014) 26-33.

[5] Wang Weixing, Lin Kai. Empirical Research of Profit Model of Science and Technology SME in Asset Light Pattern[J]. Science and Technology Management Research, 7 (2015): 185-191. 